\title{
A migration effect? Comparing the acculturation of Russian migrant populations in Western Europe to Russians in three former soviet countries on attitudes towards government responsibility
}

\author{
Troels Fage Hedegaard ${ }^{1 *}$ and Hidde Bekhuis ${ }^{2}$
}

\author{
* Correspondence: \\ troelsfh@dps.aau.dk \\ 'Department of Political Science, \\ Centre for Comparative Welfare \\ Studies, University of Aalborg, 9220 \\ Aalborg, Denmark \\ Full list of author information is \\ available at the end of the article
}

\begin{abstract}
In a number of recent articles migration has been used as a 'natural experiment', which can give insights into the general mechanisms of attitude formation. Studies from the field of psychology, however, suggest that the process of acculturation might be affected by migrants being in a particular situation. If such a 'migration effect' exists, then the conclusions on the more general mechanisms of attitude formation based on migration studies have to be rethought. We test this using a novel study design comparing acculturation in which we compare attitudes in the Russian diaspora left behind, in Estonia, Latvia and the Ukraine, by the collapse of the Soviet Union to those of Russian migrants in Germany, Denmark and the Netherlands. The results show that there are no differences in acculturation between the diaspora in the East and the migrants in the West and therefore no 'migration effect' on acculturation.
\end{abstract}

Keywords: Acculturation, Natural experiment, Migrants, Diaspora, Soviet union

\section{Introduction}

Large-scale cultural or institutional changes are rare. Though this is good for the stability of society, it also means that it is difficult to test many of the existing theories on how culture and institutions impact attitudes. Except for the few natural experiments, like the East-West German reunification (Svallfors, 2010), there are few opportunities to study instances in which we can follow how attitudes adapt to a new context or cultural changes. Partly for this reason the literature on whether migrants' attitudes acculturate has grown quite substantially over the last several years as, in addition to giving insights into the integration of migrants into new host societies, these studies also help to explore the more general mechanisms of attitude formation. Studies of migrants' attitudes have, in some instances, even been described as 'natural experiments', as they show what happens when a large group of people with varying backgrounds come into contact with a new country having a different culture and different institutions. Though the results of these studies are mixed, the majority do show that

(c) The Author(s). 2018 Open Access This article is distributed under the terms of the Creative Commons Attribution 4.0 International icense (http://creativecommons.org/licenses/by/4.0/), which permits unrestricted use, distribution, and reproduction in any medium, provided you give appropriate credit to the original author(s) and the source, provide a link to the Creative Commons license, and indicate if changes were made. 
migrants acculturate, meaning that their attitudes become more like those held by the native population than those dominant in the country of origin (Breidahl \& Larsen, 2016; Chauvet, Gubert, \& Mesplé-Somps, 2016; Dinesen, 2012; Luttmer \& Singhal, 2008; Maxwell, 2010; Reeskens \& Van Oorschot, 2015; Röder \& Mühlau, 2012; Röder \& Mühlau, 2014; Safi, 2010). This would indicate that attitudes are context-specific and thus changeable.

There might, however, be an issue with this approach of testing the mechanisms of attitude formation. A number of studies, mainly from the field of psychology, have argued that the act of migrating might be affected the willingness to adapt to the values and attitudes in a new country (Berry, Kim, Minde, \& Mok, 1987; Berry, 1997, 2001; Birman \& Trickett, 2001; Boneva \& Frieze, 2001; Main, 2014; Polek, Van Oudenhoven, \& Berge, 2011). If this is the case, then conclusions about the more general mechanisms of attitude formation might have to be reconsidered. Therefore, we want to demonstrate whether the 'migration effect' on the ability to acculturate exists.

There are, however, a number of problems related to comparing the impact of the migration dimension on acculturation, as this often entails comparisons of culturally very different groups. To overcome the problems in the literature we outline a novel design in which the collapse of the Soviet Union serves as a natural experiment. The fall of the Berlin Wall in 1989 signalled the beginning of the end for the Soviet Union, and about 2 years later the collapse was final. This meant, among many other things, that the states in the union now became sovereign nations again, which resulted in 25 million Russians becoming a 'part of a large diaspora, without moving an inch or leaving their homes' (Heleniak, 2004). Large communities of Russians therefore live in former Soviet states, and these diasporas make up a sizeable part of the population in countries like Estonia (24.8\%), Latvia (26.2\%), and Ukraine (17.3\%) (CIA World Factbook, 2011). By comparing to what degree the attitudes of ethnic Russian-living the aforementioned countries and Russian migrants living in Western Europe are similar to those of the natives in their respective countries, we will study whether this 'migrant effect' exists.

We will measure the level of acculturation to the attitudes of the natives by combining the 'European Social Survey' (ESS) from 2008 with the 'Migrants' Welfare State Attitudes' (MIFARE) survey from 2016, which was collected among ten migrant groups, including Russians, in the Netherlands, Denmark and Germany. Using this combination we will study attitudes of displaced Russians concerning whether providing healthcare for the sick, a guaranteed standard of living for the old and the unemployed, and resource redistribution should be the responsibility of government.

\section{A migration effect?}

The effect of being a migrant can be broken down into two principal components: migrating and being a minority. As we will argue below, we focus on the first and hold the latter constant, which is also why we use the term 'migration effect'. We are, however, not the first to directly or indirectly consider these two components of the migrant experience. Though a 'migration effect' has yet to be suggested elsewhere, very similar ideas do exist in other studies. In the field of 
psychology, acculturation and the psychological problems related to it form a particular area of study. In a now seminal text, Berry et al. (1987) argued that the degree to which different groups acculturate is affected by two factors: whether the group migrated (i.e. mobility) and whether contact with the native population is voluntary (i.e. voluntariness of contact). On these two dimensions, Berry et al. (1987) examine five different groups - ethnic groups, native peoples, immigrants, sojourners, and refugees - as outlined below (Table 1).

The four groups are placed into the table following the argument that while immigrants and refugees both migrated to a new country, the immigrants did this voluntarily and usually with the intention to stay, while refugees arrived in the host country by forces outside their control. This creates a difference in voluntariness of contact with natives: 'Those who are voluntarily involved in the acculturation process (e.g. immigrants) may experience less difficulty than those with little choice in the matter (e.g. refugees and native peoples), since their attitudes towards contact and change might be more positive' (Berry et al., 1987, p. 494). Immigrants and sojourners, such as expatriates and international students, both arrive in the host country voluntarily, but sojourners arrive with the intention to stay for only a limited period. On the other hand ethnic groups are born in the country, creating a difference in the mobility dimension. Ethnic groups and native people are both groups born in the 'recipient' country, and thus similar in the mobility dimension, but indigenous people differ from ethnic minorities in that the host country was involuntarily imposed upon them, for instance via colonisation, making a difference in the voluntariness of contact. The result of this, Berry et al. (1987) theorise, is that the acculturation process will be the easiest for ethnic groups and most difficult for refugees, with immigrants, sojourners and native peoples falling somewhere in-between. The impact of the mobility dimension, that is, whether the group migrated or not, should therefore be biggest when comparing migrants and native peoples.

Berry et al. (1987) tested the impact of the mobility dimension by comparing Korean immigrants to ethnic groups of Anglo-Saxon origin in Canada. They argue that this is a good test of the mobility dimension, as this 'holds the society constant' by only comparing groups in Canada. While it could be argued that this does fix the context problem, it has the problem of comparing culturally different groups. If the immigrants and ethnic groups are different in ways that controlling for socioeconomic status cannot capture, the difference could lead to a 'false positive' regarding a migration effect. Berry et al.'s (1987) argument has been repeated often and serves as one of the seminal texts in studies of acculturation, but the ideas underlying the experiment have rarely been retested (see meta-review of the literature by Nguyen \& Benet-Martínez, 2013). One of the few exceptions is an article by Sodowsky, Lai, and Plake (1991) that examines how the type of migration, in this case voluntary migration and the involuntary refugee status, affects the acculturation of Hispanic Americans and Asian Americans. This article, however, also has the issue of comparing culturally different groups and drawing

Table 1 The mobility and voluntariness of contact with natives of different groups

\begin{tabular}{lll}
\hline & Voluntary contact & Involuntary contact \\
\hline Sedentary & Ethnic groups & Native Peoples \\
Migrant & Immigrants \& Sojourners & Refugees \\
\hline
\end{tabular}


conclusions on the differences. Furthermore migrants are not comparable with refugees with respect to mental and health characteristics (see Lindert, von Ehrenstein, Priebe, Mielck, \& Brähler, 2009 for an overview), as well as on perceived acculturation stress in general (Gil \& Vega, 1996; Nwadiora \& McAdoo, 1996).

\section{The migration effect in other domains}

Following Berry's theory outlined above, we expect ethnic groups to have an easier time acculturating than migrant groups. However, the opposite conclusion is reached in other academic fields. Studies of educational success have pointed to 'migrant optimism' as the reason why the migrant groups tends to do better than resident ethnic groups (this mainly refers to African Americans and Native Americans). The argument goes that while immigrants tend to form a nonoppositional relationship with the dominant culture, native peoples or ethnic groups tend to form oppositional relationships with the dominant culture (Ogbu \& Simons, 1998). However, these studies suffer from the same problem as Berry's work, as the studies compare fundamentally different groups, mainly in the US context (Hirschman, 2001; Kao \& Tienda, 2005; Perreira, Harris, \& Lee, 2006). For instance, Kao and Tienda (2005) find that children of Asian American migrants tend to do relatively better, and children of African Americans tend to do worse than children of white Americans.

In finally, studies of migration and migration patterns have also argued for a migrant personality (Boneva \& Frieze, 2001; Polek et al., 2011). In this literature it is argued that those who choose to migrate have specific personality traits such as desire for achievement and power, and lower focus on affiliation and family, which make them more likely to migrate and which therefore also could make them more likely to acculturate (Boneva \& Frieze, 2001; Polek et al., 2011). Boneva and Frieze (2001) tested this by comparing personality traits of those who say they are willing or unwilling to migrate. Though this design does hold the cultural group and society consistent, it has the issue that the group that are willing to migrate actually have not migrated yet. Polek et al. (2011) partially solves this issue by comparing Poles who migrated to the Netherlands with Poles who stayed behind. This does test the personalities of those of migrated and those who did not, within the same cultural group. However, if we compare against the theoretical setup of Berry et al. (1987), which to be fair was not the purpose of the paper, it is problematic that the Poles who did not migrate are not an ethnic group, but the native population in Poland.

\section{Testing the migration effect}

So to recapitulate we have two issues. First of the literature related to migrants and ethnic groups acculturation gives us opposing expectations. The literature following in the footsteps of Berry et al. (1987) finds that ethnic groups have an easier time acculturating. On the other hand, the literature on 'migrant optimism' and the 'migrant personality' suggests the opposite that migrants tend to do better in terms of acculturating. Secondly, the studies have a persistent issue of comparing culturally different groups and then concluding on the differences. 
With these issues in mind, we suggest a better design to test the migration effect. We want to hold constant the country of origin and thereby avoid crosscultural comparisons that plagues the literature cited above, but still have variation on the migration dimension. Ideally, this would require that we have a group originating from the same country that are both a migrant group and an ethnic group, living within the same country. This situation we simply cannot think up, as there might situations in where groups from the same country have arrived for different reasons. However, since we want to compare migrants to an ethnic group the best approximation of the latter might be a situation where the previous country collapses and a new one arises, and as result of this a new ethnic minority group is created. This would be what Berry et al. (1987) calls an ethnic group, but in what is commonly known as a diaspora (Van Hear, 2014). If we can compare members of the diaspora with migrants from the same country of origin, we can compare the effect of migrating among the same origin group across different conditions. The only issue with this is that we still have variation in the society of the recipient country, but this we will try to account for as well as possible. The different groups we are interested in are highlighted in Fig. 1 below.

Following the argument presented above we will study the impact the migration dimension by focusing on two groups: Russian migrants in the three Western countries Denmark, the Netherlands, and Germany, and the Russian diaspora in Ukraine, Estonia, and Latvia. This gives us the ability to distinguish among the attitudes of migrants, the diaspora, and compare these to the natives in the countries being considered.

Ukraine, Estonia, and Latvia have a shared history of leaving the Soviet Union and becoming sovereign nations at about the same time. Because of this, the

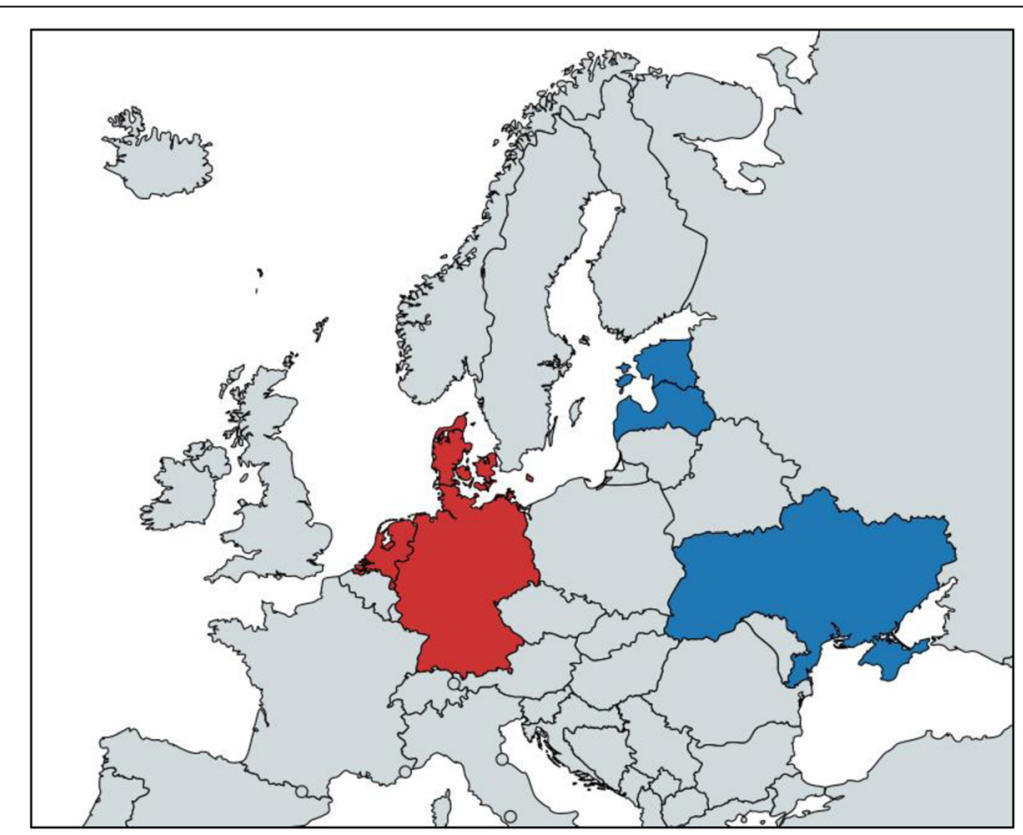

Fig. 1 Russian migrant populations in Western countries and select former Soviet states. Note: The Western countries highlighted in red are Denmark, Germany and the Netherlands. The countries highlighted in blue are Estonia, Latvia, and Ukraine 
countries all have a Russian diaspora of about the same size (17-26\%). The process of leaving the Soviet Union meant that the Russians living in these countries changed status from being part of the majority in the union to being the largest an ethnic minority in the three countries (CIA World Fact Book, 2011). This change was not initiated by the Russians living in these countries and has led to tensions and conflicts between the new ethnic group and the new majority (Heleniak, 2004; Kolstø, 1996). For instance Kolstø (1996) argues that: "The collapse of the unitary Soviet state has plunged its former citizens into a profound identity crisis. Particularly hard hit are the twenty-five million Russians living in the non-Russian successor states." (Kolstø, 1996, p. 609). The Russian diasporas in the three countries has fought hard to maintain the memory and symbols of the former Soviet empire, but are left feeling increasingly forgotten and marginalized (Aasland, 1994; Heleniak, 2006; Kesküla, 2015; Melchior \& Visser, 2011).

Denmark, the Netherlands, and Germany, all have fairly large populations of first generation migrants $(10-12 \%$ in 2015 , according to Eurostat) and a reason history of receiving migrants from most of the world (Eurostat, 2015). However, as opposed to in Ukraine, Estonia, and Latvia the Russian migrants to not make up any of the five largest migrant populations in any of the three countries. For these countries there is a potential issue of us not knowing the reason for migrating. Particularly for Germany this might be an issue in regards to the history with the East Block and the so-called 'Aussiedler', or Ethnic Germans, from the former Soviet union who are entitled to German citizenship due to their ethnic origin (Pfetsch, 1999). However, from the survey data presented in the next section, we do know when our sample of Russians in the West migrated. This was for 95\% percent of them after 1989 thus not to escape the Soviet regime. From this we cannot conclude why they migrated, but we can assume that this is mostly for non-humanitarian reasons. However, to make sure any differences to not exist then analysis will do made on a country basis also.

To sum up the argument we have two groups of Russians we aim to compare in terms of acculturation. This leaves us with three possible outcomes: First, that the diaspora acculturates more successfully than the migrants, as predicted by the literature following Berry et al. (1987). Seconly, that the Russian migrants acculturate better than the diaspora, as for instance predicted by the literature on the 'migrant optimism'. Third, that migrants and the diaspora acculturate to the attitudes of the natives about equally well, which could shine a positive light on the literature that uses migration as a 'natural experiment' that tests the mechanism of attitude formation.

\section{Data, variables and methods}

The design of the article is based on comparing the Russian diaspora in former Soviet countries with Russian migrants in other countries relative to native attitudes towards the role of the government. As there is not one data set which contains all these groups, we merged the Migrants' Welfare State Attitudes survey (MIFARE) from 2016 (Bekhuis \& Hedegaard, 2016) with the European Social 
Survey (ESS) from 2008. When using both datasets we will define and select Russians on the background of country of birth. There are other ways of defining nationality like subjective nationality or citizenship (Hedegaard, 2017), but this one allows us to compare across datasets.

The MIFARE survey was collected among ten migrant groups and natives in Denmark, the Netherlands, and Germany. In both Denmark and the Netherlands, the MIFARE sample from population registers is used. Because this was not possible in Germany, this sample is therefore based on strategically selected municipalities. This was only done in West Germany for two reasons. First, East Germany has a completely different migration and integration history than West Germany, which made it substantially more difficult to sample migrants from that part of the country. Secondly, most other analysis shows that you therefore have to treat Germany as essentially two countries, especially regarding questions of support for the welfare state (for detailed information see Bekhuis \& Hedegaard, 2016). The sample included migrants who were 16 years or older when they migrated and who were at least 18 years old during the survey. The survey was collected both online and offline, and in the mother tongue or in Danish, Dutch or German. In total, 408 Russian migrants in Denmark filled out the survey (response rate $=40.8 \%$ ), 475 Russians did so in the Netherlands (response rate = 43.2\%), and 308 Russians in Germany completed the questionnaire (response rate $=14.5 \%)$. The net samples for the native Danes, Dutch, and Germans are 397 (44.1\%), 427 (47.4\%), and $233(29.9 \%)$ respectively. For the Danish part of the survey we were able to test non-response using the social register. For the Russians this showed a slight overrepresentation of the young, non-citizens and those in the workforce, but generally the differences the response and non-response groups were minimal (Bekhuis \& Hedegaard, 2016).

The ESS is a high-quality survey based on face-to-face interviews collected every 2 years since 2002 among participating European countries. In the survey the country of birth is registered, which means that it is possible to find the migrant sub-populations. For this reason the ESS has served an important role, as it has been the empirical component of much of the current literature on migrants' attitudes and acculturation (e.g. Breidahl \& Larsen, 2016; Dinesen \& Hooghe, 2010b; Maxwell, 2010; Reeskens \& Van Oorschot, 2015; Röder \& Mühlau, 2014; Safi, 2010). In this article we will rely on the 2008 version of the ESS, as this survey included a special module on attitudes to the welfare state and the role of the government in it. Using this survey we could pinpoint Russians living Estonia ( $N=$ $224)$, Latvia $(N=153)$, and Ukraine $(N=132)$ and the natives from these countries $(N=6942)$. The percentages of Russians living in the three Western countries are higher than the percentages of Russians in Estonia, Latvia and Ukraine in the ESS, which is possibly due to the fact that ESS is not a migrant survey and therefore is not translated. This underrepresentation of Russians in the in the former Soviet countries can therefore underestimate the effect as it might rule out the least integrated Russians who do not speak the language. The recognition that the ESS has a large population of Russians in the former Soviet countries registered as migrants is not new (Dinesen, 2013). This article is, however, the first to attempt to make positive use of it. 


\section{Dependent variables}

Acculturation of values and attitudes can be and has been measured in a number of areas, including social trust (Dinesen \& Hooghe, 2010a), gender values (Breidahl \& Larsen, 2016), and support for the welfare state (Luttmer, 2001; Reeskens \& Van Oorschot, 2015). For the two survey the only possibly overlap in questions is on whether it should be the government's responsibility to provide welfare in four areas: ensuring adequate healthcare for the sick, ensuring a reasonable standard of living for the old, ensuring a reasonable standard of living for the unemployed and reducing income differences between rich and poor. For the first three dependent variables the questions were similar in the ESS and MIFARE surveys; however, the answer categories differ. Regarding the questions on the sick, old and unemployed, respondents were asked to answer on an 11-point scale from 0 to 10 in the ESS, while in the MIFARE respondents had to answer on a four point scale from 1 to 4 where 1 means no government response at all and 4 complete government responsibility. In merging these questions, the ESS categories were adjusted to the MIFARE scale. Categories 0 to 2 in the ESS were coded as 1,3 to 5 as 2,6 to 8 as 3 , and 9 and 10 as 4 . Since there is no way to divide the categories evenly we chose a 'conservative' recoding, in that we have fewer respondents going into the top, 'complete government responsibility' (4) category. ${ }^{1}$ The questions about reducing income difference could be answered in the ESS on a five-point scale with a middle category. As there was no way to fit this middle category into the fourpoint scale of the MIFARE data we did not include this answer category. ${ }^{2}$ A final point to notice on this variable is that while MIFARE asked about reducing income differences between rich and poor, the ESS did not include this phrasing. As a result we ended up with four dependent variables where the respondents answered those different tasks 'definitely should not be', 'probably should not be', 'probably should be' or 'definitely should be' a government responsibility. For this and all other variables, 'don't know' and invalid answers were not included. Mean scores by country are presented in Table 3 in Appendix.

\section{Independent variables}

To account for compositional differences, a number of variables are included in the analyses. We included age in groups that represent the history of the Soviet Union. The youngest group are those 24 years old or younger, who were socialised after the fall of the Soviet Union. Next are those 25 to 39 years old, who were children at the time of the Soviet Union. The third group are those 40 to 55 years old, who were fully socialised during the rule of the Soviet Union. Finally, those 56 years or older were also socialised during Soviet times and form the oldest age group. Gender is measured by a dummy variable, indicating if a respondent is a female or not. Religiosity is measured on a four-point scale ranging from 'not religious at all' (1) to 'very religious' (4). This variable can be included as a linear variable. Respondents' education level is measured using the internationally comparable ISCED scale ranging from 0 , no formal education, to 6, upper level tertiary. Social trust is measured using the standard question of 'generally speaking, would you say that most people can be trusted, or that you can't be too careful in dealing with people?' Higher scores on the merged scale from 1 to 5 reflect 
more trust in other people. Respondents' net household income is measured using different categories in the different countries in the ESS and in the MIFARE. In order to compare the different income categories between countries and surveys we used quartiles of the different income scales. The quartiles are calculated on a national level. In order to show the differences on the migration dimension we included a dummy on whether or not a respondent is a member of the diaspora. Respondents in Estonia, Latvia and Ukraine are counted as part of the diaspora, whereas respondents in Denmark, Germany and the Netherlands are counted as migrants.

\section{Methods}

The analyses were done in two steps. First, the means of the four different dependent variables were shown by group. T-tests were used to show significant differences between those groups. The means by age group were also presented to show whether or not differences are caused by age or generation effects.

Second, fixed effects regression analyses on the four different dependent variables were made. The data has a multilevel structure as respondents are nested in countries. This number of nesting groups is too low to meet the assumptions for multilevel analyses (Hox, 2010). However, to still reckon with the multilevel structure, we make fixed effects models, which account for clustering on a country level, but do not add any macro level variables to explain this clustering. In the regression models only the attitudes of the Russians abroad were included. To show whether or not the attitudes of the Russian left-behinds and Russian migrants were affected by native populations, the mean attitude of the natives in a country was included in the analyses. A significant influence, or the lack thereof, from the variable diaspora tells if the diaspora and the migrants differ significantly from each other or not. A positive figure means that diaspora Russians are more in favour of government responsibility than migrant Russians, where a negative figure means the opposite.

\section{Results}

We start by showing the different attitudes of diaspora of Russians living in Estonia, Latvia and Ukraine (headlined as diaspora), Russian migrants living in Denmark, the Netherlands and Germany (migrants), natives from Estonia, Latvia and Ukraine (natives East), and natives from Denmark, the Netherlands and Germany (natives West). In Fig. 2 the mean score on attitudes towards government responsibility is presented. To iterate, the questions about government responsibility are on a four-point scale, from 'definitely should not be' (1) to 'definitely should be' (4).

Figure 2 shows an overall tendency for the migrants and the diaspora to be more in favour in government responsibility than the natives, but also more in agreement with their respective paring of natives in the East and the West. Examining the support for the government providing a reasonable standard of living for the sick, the diaspora (3.81) and migrants (3.80) express slightly more support for this than the natives in the Baltics (3.71) and Western countries (3.75). However, considering that the question runs on a scale from 1 to 4 these differences between the groups are very small and in most cases insignificant (not shown). 


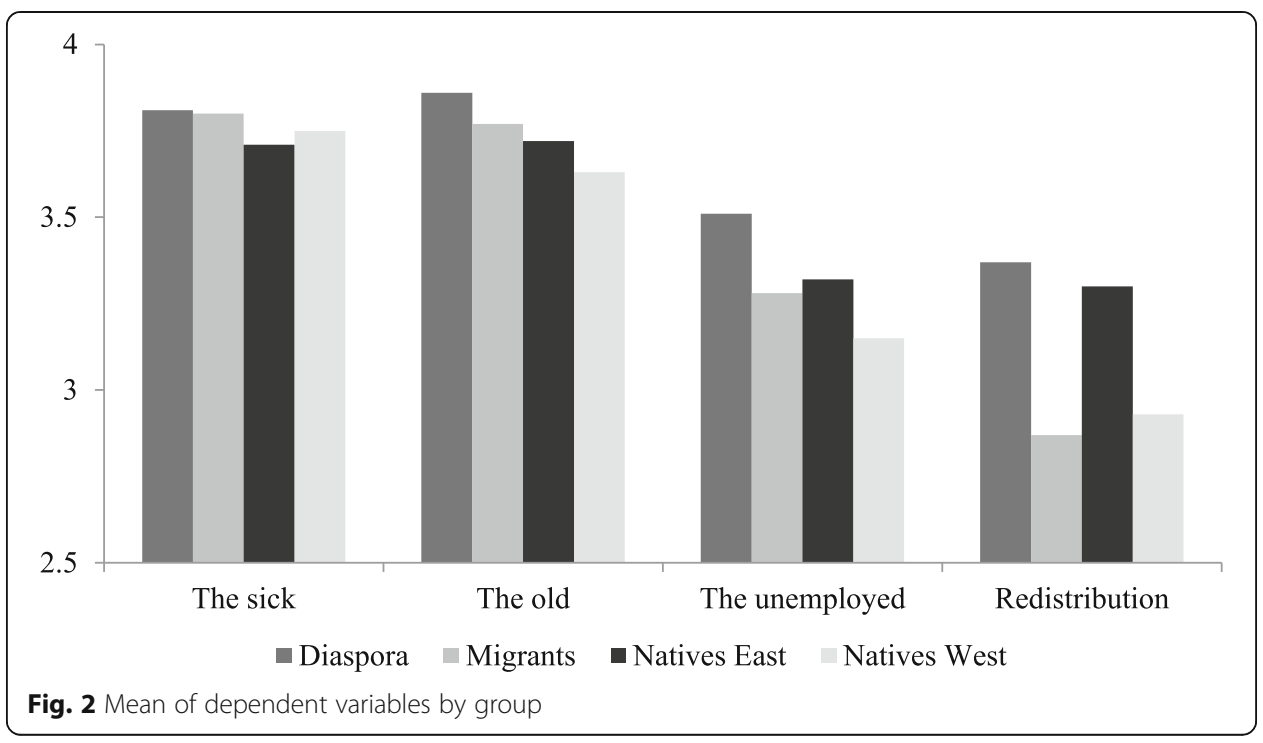

Regarding government's responsibility to provide a standard of living for the old, we see that the diaspora (3.86) has the strongest preference for more responsibility. This is followed by the migrants (3.77) and natives in the East (3.72) and the West (3.63). There is thus a sort of paring where the migrants and the natives in both the East and the West are more internally alike than different. The same overall pattern is observed in regards to attitudes government responsibility for providing a reasonable standard of living for the unemployed. There we again see that both the diaspora (3.51) and migrants (3.28) favour a larger role for government than do the respective natives (3.32 and 3.15). Finally, regarding the role of the government in redistribution, attitudes are quite divergent between the diaspora (3.37) and migrants (2.87), with the diaspora preferring significantly more government responsibility in this area. This, however, seems to follow the differences between natives East (3.30) and West (2.93).

Overall, Fig. 2 shows that the diaspora and migrants would prefer government to take more responsibility for providing welfare in these four areas than natives in the East and West do. However, we again see that the diaspora are more similar to the natives in the East than those in the West and the same is true for the migrants in the West. Next, we will present a regression analysis to test whether this pattern also holds when accounting for compositional and contextual factors.

Table 2 shows the results of fixed effects regression analyses. In this model, only Russians in the Baltic countries, Ukraine and the Western countries are included. Since acculturation is measured in comparison to natives, the natives' attitudes are included as an aggregated country mean. This variable, together with a dummy variable indicating whether someone belongs to a diaspora or is a migrant, enables us to test whether or not diaspora residents and migrants differ from each other, and whether the attitudes are affected by attitudes of the natives.

The diaspora variable shows the effect of being a part of the diaspora as opposed to being a migrant. A significant effect on the diaspora variable would mean that the Russian diaspora in the Ukraine and the two Baltic countries are different in attitude from 
Table 2 Fixed effects regression models on attitudes to government responsibility. Coefficients and significance levels reported

\begin{tabular}{|c|c|c|c|c|}
\hline & $\begin{array}{l}\text { Standard of living } \\
\text { for the sick }\end{array}$ & $\begin{array}{l}\text { Standard of living } \\
\text { for the old }\end{array}$ & $\begin{array}{l}\text { Standard of living for } \\
\text { the unemployed }\end{array}$ & $\begin{array}{l}\text { Redistribution between } \\
\text { rich and poor }\end{array}$ \\
\hline $\begin{array}{l}\text { Diaspora (versus } \\
\text { migrants) }\end{array}$ & -0.0288 & -0.0969 & -0.0712 & 0.215 \\
\hline Natives & 0.229 & $0.406^{*}$ & $0.560^{* * *}$ & $0.445^{* *}$ \\
\hline Age $($ ref $=>56)$ & ref & ref & ref & ref \\
\hline $55-40$ & -0.0674 & $-0.0955^{* *}$ & -0.0776 & -0.124 \\
\hline $39-25$ & $-0.126^{* *}$ & -0.0752 & $-0.210^{* *}$ & -0.171 \\
\hline$<25$ & -0.0781 & $-0.165^{* *}$ & $-0.458^{* * *}$ & -0.207 \\
\hline Age $($ ref $=>56)$ & 0.0457 & 0.0386 & 0.0616 & 0.00658 \\
\hline Religiosity (1-4) & 0.0191 & 0.0265 & 0.0332 & $0.0822^{*}$ \\
\hline $\begin{array}{l}\text { Income (ref = 1st } \\
\text { quartile) }\end{array}$ & ref & ref & ref & ref \\
\hline 2nd quartile & -0.00386 & -0.0243 & -0.0999 & -0.0785 \\
\hline 3rd quartile & $-0.0937^{* *}$ & -0.0620 & $-0.236^{* * *}$ & $-0.160^{*}$ \\
\hline 4th quartile & -0.0682 & $-0.0854^{*}$ & $-0.308^{* * *}$ & $-0.415^{* * *}$ \\
\hline $\begin{array}{l}\text { Education } \\
(\text { ref = ISCED 0) }\end{array}$ & ref & ref & ref & ref \\
\hline ISCED 1 & 0.118 & 0.113 & $0.298^{*}$ & 0.0802 \\
\hline ISCED 2 & 0.0673 & 0.0932 & 0.0541 & 0.152 \\
\hline ISCED 3 & 0.0814 & 0.0836 & 0.154 & -0.117 \\
\hline ISCED 4 & 0.0807 & $0.167^{*}$ & 0.157 & -0.0694 \\
\hline ISCED 5 & 0.0143 & 0.0628 & 0.0348 & -0.119 \\
\hline ISCED 6 & 0.0455 & 0.0820 & -0.0674 & -0.0665 \\
\hline Social trust $(1-5)$ & 0,00117 & 0,0000482 & $0,0482^{* *}$ & 0,0239 \\
\hline Constant & $2.789^{* * *}$ & $2.387^{* * *}$ & $1.500^{* *}$ & $1.345^{*}$ \\
\hline $\mathrm{N}$ & 1401 & 1397 & 1374 & 1285 \\
\hline
\end{tabular}

Note: Note: Based on merging ESS and MIFARE data

${ }^{*} p<0.05 ;{ }^{* *} p<0.01 ;{ }^{* * *} p<0.001$

Russian migrants in Denmark, Germany and the Netherlands. A negative effect means that diaspora are less in favour of government responsibility than migrants, and a positive sign means the opposite. It appears that there are no significant differences between diaspora and migrants on all the four attitudes, meaning that after controlling for compositional characteristics, there is no difference between the diaspora and migrants in how they adjust to the receiving society. The idea that those who migrate voluntarily have a mind-set or personality which should result in quicker acculturation to the host society, in other words the 'migrant effect', cannot be confirmed.

Looking at the other effects in Table 2, we can see that natives' attitude has a positive effect on the attitude towards government responsibility for the old, the unemployed, and redistribution. This shows that natives' attitudes affect the attitudes of the Russian diaspora and migrants, except towards responsibility for the sick. Regarding age, it appears that the youngest are in favour of less government responsibility for the old, the unemployed, and redistribution, similar to what was reported in Fig. 2 above. The pattern is, however, not as clear-cut as above, possibly because including other composition effects captures some of the differences between the age groups. Religiosity only has a significant effect on attitudes towards redistribution. The effect here is positive, meaning that the more religious someone 
is, the more he or she thinks that the government is responsible for income redistribution (Kahl, 2005). Income does not affect opinion about role of the government in providing for the old, but affects the other three attitudes. Here the pattern is, not surprisingly, that those who belong to the higher income quantiles see a smaller role for the government. This is in line with classic class-based arguments regarding the role of the welfare state in society (Svallfors, Kulin, \& Schnabel, 2012). Education level has no effect at all.

Finally, it can be argued that length of stay in the country may have an effect. Russian migrants in the Western European countries have stayed, on average, in the countries for 11 years, while the majority of the Russian diaspora in Eastern Europe have been there for more than 20 years. Length of stay could not be included in the models as it creates multicollinearity with the age variable, as the older also have stayed longer. To account for this we ran two additional models with only migrants and diaspora who have been in the country for at least 10 years and at least 20 years (not shown). The additional models show the same non-effects, which again leads to the conclusion that we cannot demonstrate the 'migration effect'.

\section{Implications and limitations}

A number of studies that have come out in recent years focus on migrants' attitudes and whether migrants acculturate, meaning whether they adapt to become more like the natives. The studies predominantly show that migrants' attitudes are contextspecific and therefore adaptable (Breidahl \& Larsen, 2016; Luttmer \& Singhal, 2008; Maxwell, 2010; Reeskens \& Van Oorschot, 2015; Röder \& Mühlau, 2014; Safi, 2010). In addition to informing the debate on integration of migrants, these studies have also been used to explore the general mechanisms of attitude formation, as migration is seen as a 'natural experiment' in which we can observe whether changing context can also change attitudes. Drawing on theories, mainly from psychology, we argue that this praxis of using migration to test the mechanisms of attitude formation might be problematic if being a migrant alone has an impact on acculturation.

To explore this we outline a study design relying on a true natural experiment: the collapse of the Soviet Union. This historic event resulted in a diaspora of upwards of 25 million people 'left behind' in countries that used to belong to the union. The Russian diaspora became a minority in the new countries involuntarily. By comparing their acculturation to that of Russians who migrated voluntarily, we are the first to test the 'migration effect'. Compared to the existing literature, this design has the advantage that we can pinpoint the effect of migrating, while keeping the effect of origin country and culture constant. Based on the literature we outlined three possible scenarios: First, that the diaspora acculturates more successfully than the migrants, as predicted by the literature following Berry et al. (1987). Secondly, that the Russian migrants acculturate better than the diaspora, as for instance predicted by the literature on the 'migrant optimism'. Third, that migrants and the diaspora acculturate to the attitudes of the natives about equally well. If we did not find the latter scenario to be the most realistic then current research on the adaptation of attitude formation to a new context might have overestimated, or underestimated, the effect of context and institutions.

To test this we merged the fourth version of the European Social Survey with the Migrants' Welfare State Attitudes survey. By combining the two surveys we were able to compare diaspora Russians in Estonia, Latvia and Ukraine, and Russian migrants in 
Denmark, the Netherlands and Germany, with each other and with natives in the respective countries. The results showed that the Russian diaspora in the two Baltic countries and Ukraine did in fact prefer a more extensive responsibility for the government in providing welfare, which could be interpreted as initial support for the migration effect. However, the results also show that this difference is mainly due to the diaspora on average being older and poorer. Therefore, when controlling for these factors, there was no difference in acculturation to natives' attitudes between migrants and the diaspora.

Although we argue that the 'migrant effect' did not exist, there are some limitations on the research design which should be improved before stating that a migrant personality, regardless of context and country of origin, does not exist. The perfect design would require the migrants and diaspora to be within the same context. It is, however, hard to imagine a situation in the real world where this could be the case. With that in mind, it is a limitation that we might not capture all contextual differences in the study. Second, we only explore this using Russians as the case. We see no reason why Russians should be more or less likely than other nationalities to acculturate, but more variation in nationality would of course strengthen the conclusion. Third, the Russian diaspora is quite homogeneous in terms of factors like age, income, and education. It would have been good to have more variation to test the impact of these factors; however, given the nature of the experiment this was not possible. Finally, there is the everpresent question of self-selection. According to Heleniak (2004), there has always been a steady flow of migration between Russia and the bordering countries. However, from the 1930s onwards, policies were implemented that facilitated increased migration from Russia to the other states in the union. This resulted in an increased net migration especially to urban areas, in which the Russians could form communities. Though the initial migration was voluntary, it cannot be ruled out that the decision to migrate before the fall of the Soviet Union and not to return after, which 2.1 million Russians did, does signify some level of self-selection. Of the migrants we looked at in Western Europe, less than $1 \%$ migrated before the fall of the union. Therefore, though we don't know specific reasons for migrating, we can presume that the action was voluntary and not a flight from Soviet rule. However, as with those who initially migrated to the Eastern countries but from the opposite point of view, it is impossible to know whether there is an element of self-perceived compulsion.

Despite these limitations, we believe that this study is the best possible test of the 'migrant effect'. For the growing field of migration studies this means that migration can be used to study attitude formation in a more general sense. Migrant surveys show not only attitudes of a select group of people from a certain origin country, but the attitudes of people from a certain origin country who are adapting to their new environment. The question for further research is how fast will this process of acculturation of attitudes go, and which factors affect the speed of the acculturation process.

\section{Endnotes}

${ }^{1}$ We have also run the model using a version where the lowest category was made the smallest, but this did not substantially change the results.

${ }^{2}$ We have run the model also with the middle category included onetime in the negative and onetime in the more positive direction. As expected due to the bigger numbers the effect sizes became larger, but did not result in different conclusions. 


\section{Appendix}

Table 3 Descriptive statistics on the variables used for analysis

\begin{tabular}{|c|c|c|}
\hline & Diaspora & Migrants \\
\hline \multicolumn{3}{|l|}{ Respondents' attitudes } \\
\hline Standard of living for the sick (mean 1-4) & 3.81 & 3.80 \\
\hline Standard of living for the old (mean 1-4) & 3.85 & 3.78 \\
\hline Standard of living for the unemployed (mean 1-4) & 3.49 & 3.28 \\
\hline Redistribution between rich and poor (mean 1-4) & 3.39 & 2.89 \\
\hline \multicolumn{3}{|l|}{ Age } \\
\hline$>56$ & $79.9 \%$ & $13.1 \%$ \\
\hline $55-40$ & $15.9 \%$ & $36.1 \%$ \\
\hline $39-25$ & $3.9 \%$ & $39.3 \%$ \\
\hline$<25$ & $0.2 \%$ & $11.4 \%$ \\
\hline \multicolumn{3}{|l|}{ Gender } \\
\hline Male & $25.4 \%$ & $32.2 \%$ \\
\hline Female & $74.6 \%$ & $67.8 \%$ \\
\hline Religiosity (mean 1-4) & 2.61 & 1.99 \\
\hline Income in quartiles (mean 1-4) & 2.12 & 2.28 \\
\hline \multicolumn{3}{|l|}{ Education } \\
\hline ISCED 0 & $8.0 \%$ & $1.6 \%$ \\
\hline ISCED 1 & $18.0 \%$ & $0.2 \%$ \\
\hline ISCED 2 & $14.5 \%$ & $2.4 \%$ \\
\hline ISCED 3 & $17.1 \%$ & $16.9 \%$ \\
\hline ISCED 4 & $18.5 \%$ & $9.2 \%$ \\
\hline ISCED 5 & $8.1 \%$ & $67.5 \%$ \\
\hline ISCED 6 & $15.5 \%$ & $2.2 \%$ \\
\hline Social trust (mean 1-5) & 2.92 & 2.97 \\
\hline \multicolumn{3}{|l|}{ Natives' attitudes } \\
\hline Standard of living for the sick (mean 1-4) & 3.67 & 3.75 \\
\hline Standard of living for the old (mean 1-4) & 3.68 & 3.62 \\
\hline Standard of living for the unemployed (mean 1-4) & 3.26 & 3.15 \\
\hline Redistribution between rich and poor (mean 1-4) & 3.25 & 2.94 \\
\hline N total & 432 & 984 \\
\hline
\end{tabular}

Note: Based on merging ESS and MIFARE data

\section{Abbreviations}

CIA: Central Intelligence Agency; ESS: The European Social Survey; ISCED: International Standard Classification of Education; MIFARE: The Migrant's Attitudes to Welfare Survey

\section{Funding}

The NORFACE "Welfare State Futures" programme funded the latter project, but did not control the design, collection, analysis, and interpretation of data.

\section{Availability of data and materials}

The "European Social Survey" (ESS) supporting the conclusions of the article is available on the ESS homepage in http://www.europeansocialsurvey.org/data/. The "Migrant's Attitudes to Welfare" (MIFARE) survey supporting the conclusions of the article will be made available via GESIS after March 1st 2018.

\section{Authors' contributions}

The authors contributed equally to the article. Both authors read and approved the final manuscript. 
Competing interests

The authors declare that they have no competing interests.

\section{Publisher's Note}

Springer Nature remains neutral with regard to jurisdictional claims in published maps and institutional affiliations.

\section{Author details}

'Department of Political Science, Centre for Comparative Welfare Studies, University of Aalborg, 9220 Aalborg, Denmark. ${ }^{2}$ Department of Sociology, University of Radboud University Nijmegen, PO Box 9104, 6500 Nijmegen, HE, Netherlands.

Received: 27 September 2017 Accepted: 14 February 2018

Published online: 02 May 2018

\section{References}

Aasland, A. (1994). The russian population in latvia: An integrated minority? The Journal of Communist Studies and Transition Politics, 10(2), 233-260.

Bekhuis, H., \& Hedegaard, T. F. (2016). MIFARE survey: Migrants' welfare state attitudes methodological report. (methodological report). Nijmegen: Univeristy of Nijmegen.

Berry, J. (2001). A psychology of immigration. Journal of Social Issues, 57(3), 615-631. https://doi.org/10.1111/ $0022-4537.00231$

Berry, J. W. (1997). Immigration, acculturation, and adaptation. Applied Psychology, 46(1), 5-34.

Berry, J. W., Kim, U., Minde, T., \& Mok, D. (1987). Comparative studies of acculturative stress. International Migration Review, 491-511.

Birman, D., \& Trickett, E. J. (2001). Cultural transitions in first-generation immigrants acculturation of soviet jewish refugee adolescents and parents. Journal of Cross-Cultural Psychology, 32(4), 456-477.

Boneva, B. S., \& Frieze, I. H. (2001). Toward a concept of a migrant personality. Journal of Social Issues, 57(3), 477-491.

Breidahl, K. N., \& Larsen, C. A. (2016). The Myth of Unadaptable Gender Roles: Attitudes towards Women's Paid Work among Immigrants across 30 European countries. Journal of European Social Policy, 26(5), 387-401. https://doi.org/ $10.1177 / 0958928716664292$.

Chauvet, L., Gubert, F., \& Mesplé-Somps, S. (2016). Do migrants adopt new political attitudes from abroad? Evidence using a multi-sited exit-poll survey during the 2013 malian elections. Comparative Migration Studies, 4. Retrieved from https://comparativemigrationstudies.springeropen.com/articles/10.1186/s40878-016-0033-z.

CIA World Factbook (2011). Retrieved from https://www.cia.gov/library/publications/the-world-factbook/.

Dinesen, P. T. (2012). Does generalized (dis)trust travel? Examining the impact of cultural heritage and destination-country environment on trust of immigrants. Political Psychology, 33(4), 495-511. https://doi.org/10.1111/j.1467-9221.2012.00886.x.

Dinesen, P. T. (2013). Where you come from or where you live? Examining the cultural and institutional explanation of generalized trust using migration as a natural experiment. European Sociological Review, 29(1), 114-128.

Dinesen, P. T., \& Hooghe, M. (2010a). When in rome, do as the romans do: The acculturation of generalized trust among immigrants in western europe. International Migration Review, 44(3), 697-727.

Dinesen, P. T., \& Hooghe, M. (2010b). When in rome, do as the romans do: The acculturation of generalized trust among immigrants in western europe. International Migration Review, 44(3), 697-727.

Eurostat (2015). Retrieved from http://ec.europa.eu/eurostat/web/population-demography-migration-projections.

Gil, A. G., \& Vega, W. A. (1996). Two different worlds: Acculturation stress and adaptation among cuban and nicaraguan families. Journal of Social and Personal Relationships, 13(3), 435-456.

Hedegaard, T. F. (2017). Indvandrergrupper og etniske minoriteter i surveys [Immigrant groups and ethnic minorities in surveys]. In M. Frederiksen, P. Gundelach, \& R. S. Nielsen (Eds.), Survey, (p. 419). Copenhagen: Hans Reitzels Forlag.

Heleniak, T. (2004). Migration of the russian diaspora after the breakup of the soviet union. Journal of International Affairs, 57, 99-117.

Heleniak, T. (2006). Latvia looks west, but legacy of soviets remains. Migration Information Source.

Hirschman, C. (2001). The educational enrollment of immigrant youth: A test of the segmented-assimilation hypothesis. Demography, 38(3), 317-336.

Hox, J. J. (2010). Multilevel analysis: Techniques and applications. Oxford: Taylor \& Francis.

Kahl, S. (2005). The religious roots of modern poverty policy: Catholic, lutheran, and reformed protestant traditions compared. European Journal of Sociology, 46(1), 91-126. https://doi.org/10.1017/S0003975605000044

Kao, G., \& Tienda, M. (2005). Optimism and achievement: The educational performance of immigrant youth. The New Immigration: An Interdisciplinary Reader, 331-343.

Kesküla, E. (2015). Reverse, restore, repeat! Class, ethnicity, and the russian-speaking miners of estonia. Focaal, 2015(72), 95-108.

Kolstø, P. (1996). The new russian diaspora-an identity of its own? Possible identity trajectories for russians in the former soviet republic. Ethnic and Racial Studies, 19(3), 609-639.

Lindert, J., von Ehrenstein, O. S., Priebe, S., Mielck, A., \& Brähler, E. (2009). Depression and anxiety in labor migrants and refugees-a systematic review and meta-analysis. Social Science \& Medicine, 69(2), 246-257.

Luttmer, E. F. P. (2001). Group loyalty and the taste for redistribution. Journal of Political Economy, 109(3), 500-528.

Luttmer, E. F. P., \& Singhal, M. (2008). Culture, context, and the taste for redistribution,

Main, I. (2014). High mobility of polish women: The ethnographic inquiry of barcelona. International Migration, 52(1), 130-145.

Maxwell, R. (2010). Trust in government among british muslims: The importance of migration status. Political Behavior, 32(1), 89-109. 
Melchior, I., \& Visser, O. (2011). Voicing past and present uncertainties: The relocation of a soviet world war II memorial and the politics of memory in estonia. Focaal, 2017(59), 33-50.

Nguyen, A. D., \& Benet-Martínez, V. (2013). Biculturalism and adjustment: A meta-analysis. Journal of Cross-Cultural Psychology, 44(1), 122-159.

Nwadiora, E., \& McAdoo, H. (1996). Acculturative stress among amerasian refugees: Gender and racial differences. Adolescence, 31(122), 477-488.

Ogbu, J. U., \& Simons, H. D. (1998). Voluntary and involuntary minorities: A cultural-ecological theory of school performance with some implications for education. Anthropology \& Education Quarterly, 29(2), 155-188.

Perreira, K. M., Harris, K. M., \& Lee, D. (2006). Making it in america: High school completion by immigrant and native youth. Demography, 43(3), 511-536.

Pfetsch, B. (1999). "In Russia we were Germans, and now we are Russians."-dilemmas of identity formation and and communication among German-Russian Aussiedler (Discussion Paper FS III 99-103). Retrieved from https://www. econstor.eu/obitstream/10419/49827/1/312915594.pdf

Polek, E., Van Oudenhoven, J. P., \& Berge, J. M. T. (2011). Evidence for a "migrant personality": Attachment styles of poles in poland and polish immigrants in the netherlands. Journal of Immigrant \& Refugee Studies, 9(4), 311-326.

Reeskens, T., \& Van Oorschot, W. (2015). Immigrants' attitudes towards welfare redistribution. An exploration of role of government preferences among immigrants and natives across 18 european welfare states. European Sociological Review, 31(4), 433-445

Röder, A., \& Mühlau, P. (2012). Low expectations or different evaluations: What explains immigrants' high levels of trust in host-country institutions? Journal of Ethnic and Migration Studies, 38(5), 777-792.

Röder, A., \& Mühlau, P. (2014). Are they acculturating? europe's immigrants and gender egalitarianism. Social Forces, 92(3), 899-928.

Safi, M. (2010). Immigrants life satisfaction in europe: Between assimilation and discrimination. European Sociological Review, 26(2), 159-176.

Sodowsky, G. R., Lai, E. W. M., \& Plake, B. S. (1991). Moderating effects of sociocultural variables on acculturation attitudes of hispanics and asian americans. Journal of Counseling \& Development, 70(1), 194-204.

Svallfors, S. (2010). Policy feedback, generational replacement and attitudes to state intervention: Eastern and western germany, 1990-2006. European Political Science Review, 2(1), 119-135.

Svallfors, S., Kulin, J., \& Schnabel, A. (2012). Age, class, and attitudes towards government responsibilities. In S. Svallfors (Ed.), Contested welfare states. Welfare attitudes in europe and beyond (1st ed., pp. 158-193).

Van Hear, N. (2014). Refugees, diasporas and transnationalism. The Oxford Handbook of Refugee and Forced Migration Studies, 176.

Submit your manuscript to a SpringerOpen ${ }^{\mathcal{O}}$ journal and benefit from:

- Convenient online submission

- Rigorous peer review

Open access: articles freely available online

- High visibility within the field

- Retaining the copyright to your article

Submit your next manuscript at $\gg$ springeropen.com 